Jurdimas (Jurnal Pengabdian Kepada Masyarakat) Royal

Vol. 2 No. 1, Jan 2019, hlm. 27 - 32

ISSN 2614-7912 (Print)

DOI: https://doi.org/10.33330/jurdimas.v2i1.291

ISSN 2622-3813 (Online)

Available online at https://jurnal.stmikroyal.ac.id/index.php/jurdimas

\title{
PEMBINAAAN BAGI PEKERJA PT MANDOM INDONESIA BATAM DALAM MENINGKATKAN COMPETENCE ENGLISH FRONTLINER
}

\author{
Ance Jusmaya*, Crisnova Katalonika Siahaan \\ Bahasa Inggris, Universitas Putera Batam \\ email: jusmayaance@gmail.com
}

\begin{abstract}
Abstrak: Menurunnya minat membaca di kalangan English is an international language, so that the application of English covers all aspects of people's lives, especially in a company. The application of English can be seen in the company PT. Mandom Indonesia Batam, where some staff in certain parts such as frontliners, receptionists, ambassadors, and marketing must be able to use English because they are serving as reception guests both locally and internationally. Becouse of the importance of the role of English in PT. Mandom Batam Indonesia in interacting with guests, the workers there should be given the training in the application of the principles of cooperation and greetings in English (address forms). So that, they can create a positive impression while working.It can be important becouse Indonesian is famous for their modesty. cooperative principle).This is based on the theory of Grice in Crabtree (2003) that in communicating every speaker and speaker must be able to understand the four principles of cooperation in communication, among others, quality maxim, quantity maxim, maximance relevance and manner maxim. The training uses the lecture method and direct interaction with the training participants with interactive practice techniques on the material regarding the principles of communication cooperation (address forms.) From this service results can be seen increasing the understanding and skills of workers at PT Mandom Indonesia Batam on the principle of cooperation and greetings in English
\end{abstract}

Keywords: English Competence, Frontliner, Address form

Abstrak: Bahasa Inggris adalah bahasa Internasional sehingga penerapan bahasa inggris meliputi semua aspek kehidupan masyarakat terutama di sebuah perusahaan. Penerapan bahasa inggris dapat terlihat pada perusahaan PT. Mandom Indonesia Batam, dimana sebagian staff pada bagian tertentu seperti front liner, receptionist, ambassador, dan marketing harus mampu menggunakan bahasa inggris karna bertugas sebagai penerima tamu baik lokal maupun internasional. Melihat akan pentingnya peranan bahasa Inggris di PT. Mandom Indonesia Batam di dalam berinteraksi kepada tamu maka perlu kiranya diberikan pelatihan bagi perkerja di dalam penerapan prinsip kerjasama dan sapaan dalam bahasa Inggris (address forms) agar dapat menimbulkan kesan yang positif dari tamu asing terhadap sikap pekerja lokal yang terkenal dengan kesopanannya.Prinsip kerjasama (cooperative principle) ini didasari pada teori Grice di (Crabtree, 2013) bahwa di dalam berkomunikasi setiap penutur dan tertutur harus dapat memahami empat prinsip kerjasama di dalam berkomunikasi antara lain, quality maxim, quantity maxim,relevance maxim dan manner maxim. Pelatihan menggunakan metode ceramah dan interaksi langsung terhadap peserta pelatihan dengan teknik interactive practice terhadap materi mengenai prinsip kerjasama komunikasi dan (address forms.) Dari hasil pengabdian ini dapat terlihat peningkatan pemahaman dan keterampilan pekerja di PT Mandom Indonesia Batam terhadap prinsip kerjasama dan sapaan dalam bahasa Inggris

Kata kunci: Kompetensi Bahasa Inggris,Frontliner,Address Form 
Jurdimas (Jurnal Pengabdian Kepada Masyarakat) Royal

Vol. IV No. 2, Des 2018, hlm. 27 - 32

ISSN 2407-1811 (Print)

DOI: https://doi.org/10.33330/jurdimas.v2i1.101

ISSN 2550-0201 (Online)

Available online at http://jurnal.stmikroyal.ac.id/index.php/jurdimas

\section{PENDAHULUAN}

Competence English Frontliner bagi pekerja PT Mandom Indonesia Batam adalah nama tema pengabdian masyarakat yang dilaksanakan oleh dosen Universitas Putera Batam di PT Mandom Indonesia Batam. Pengambilan tema ini karna berhubungan dengan keahlian dan skill yang dimiliki oleh Pengabdi dan berkaitan dengan kebutuhan yang diperlukan oleh pekerja di PT Mandom Indonesia Batam. Dengan adanya pembinaan ini diharapkan pekerja di PT Mandom Indonesia Batam dapat memiliki kemampuan di dalam penguasaan bahasa Inggris dan dapat menjadi frontliner yang baik bagi pekerja asing atau lokal yang berkunjung atau memiliki hubungan bisnis.

Frontliner adalah pekerja yang memiliki peranan yang amat penting di dalam sebuah perusahaan. Baik perusahaan lokal, nasional maupun perusahaan Internasional. Karna memiliki peranan yang amat penting maka dapat disimpulkan bahwa frontliner adalah 'wajah' dari sebuah perusahaan. Makna 'wajah' dapat di artikan sebagai cerminan dari sebuah perusahaan atau baik buruknya perusahaan dapat diukur dari pelayanan dan komunikasi yang dilakukan oleh frontliner. Melihat phenomena pekerja frontliner yang ditemukan oleh pengabdi pada PT mandom yang belum mampu menguasai bahasa Inggris secara baik dan benar khususnya bagaimana cara menerapkan teknik penyapaan terhadap tamu asing yang datang keperusahaan. Keadaan ini didukung oleh pihak manajemen melalui keluhan yang disampaikan kepada pengabdi saat obeservasi lokasi.

Mengingat akan pentingnya peranan frontliner ini bagi perusahaan maka perlu kiranya diberikan pembinaan bagi pekerja di PT Mandom Indonesia Batam untuk menumbuhkan etos kerja yang baik dan dapat memberikan kesan yang baik bagi pekerja lokal khususnya kota Batam dimata dunia

Prinsip kerjasama (cooperative principle) adalah sebuah metode komunikasi yang diprakasai oleh seorang ahi bahasa bernama Grice. Dalam theorinya, Grice dalam (Crabtree, 2013) mengatakan bahwa dalam melakukan komunikasi hendaklah penutur dan tertutur dapat menerapkan empat prinsip kerjasama yang dikenal dengan istilah maksim. Empat maksim yang dimaksud adalah maksim kuantitas, maksim kualitas, maksim relevan dan maksim sikap.

Prinsip kuantitas atau yang dikenal dengan quantity maxim adalah prinsip komunikasi dimana sipenutur harus meberikan informasi yang sesuai dengan yang dibutuhkan oleh tertutur secara singkat dan cukup. Pada maksim ini si penutur tidak boleh meberikan informasi yang berlebihan di luar apa yang ditanyakan oleh si penutur lain. Sementara itu maksim kualitas atau yang dikenal dengan quality maxim adalah prinsip kerjasama komunikasi yang mengedepankan nilai-nilai kejujuran di dalam menyampaikan informasi kepada orang lain. Jika orang bertanya apa it A? Maka jawablah degam jujur apa yang ditanyakan. Penutur tidak boleh menyimpang dari kebenaran sebuar pertanyaan yang diajukan.

Prinsip Relevan atau yang disebut dengan Relevance Maxim adalah maksim yang mengedepankan 
Jurdimas (Jurnal Pengabdian Kepada Masyarakat) Royal

Vol. IV No. 2, Des 2018, hlm. 27 - 32

ISSN 2407-1811 (Print)

DOI: https://doi.org/10.33330/jurdimas.v2i1.101

ISSN 2550-0201 (Online)

Available online at http://jurnal.stmikroyal.ac.id/index.php/jurdimas

nilai-nilai saling memahami apa yang dimaksudkan oleh si penutur kepada tertutur. Jawaban yang diberikan harus sesuai dan berhubungan dengan topik pembicaraan yang dilakukan. Sedangkan maksim sikap atau manner maxim adalah prinsip kerjasama dalam komunikasi yang mengedepankan keteraturan dari susuna kata-kata dan cerita yang kita sampaikan. Pehenomena yang disampaikan harus jelas dan tidak menimbulkan interpretasi yang berbeda atau pemahaman yang tidak jelas dari apa yang ingin ditanya oleh si penutur.

Melihat phenomena akan pentingnya penerapan prinsip kerjasama dan kata sapaan bagi pekerja dalam melakukan komunikasi dalam menunjang kinerja pekerja, maka pengabdi menilai perlu kiranya diadakan pelatihan mengenai penerapan prinsip kerjasama dan kata sapaan dalam bahasa ingris di PT Mandom Indonesia Batam.

Kegiatan pengabdian ini memberikan solusi terhadap masalah yang dijabarkan diatas dengan cara antara lain:

1. Memberikan pelatihan kepada pekerja frontliner PT Mandom Indonesia Batam mengenai prinsipprinsip kerjasama berkomunikasi dalam bahasa Inggris yang dapat dijadikan sebagai modal dasar dalam melayani tamu asing perusahaan PT Mandom Indonesia Batam

2. Memberikan pelatihan kepada pekerja frontliner PT Mandom Indonesia Batam mengena bahasa sapaan dalam bahasa Inggris agar dapat menyambut dan menyapa tamu asing sesuai dengan kaedah bahasa Inggris yang berlaku serta dapat memberikan respon positif dari tamu asing yang disambut.

\section{METODE}

Untuk mencapai target dalam kegiatan pelatihan ini, maka peneliti menawarkan metode untuk menyelesaikan masalah yang telah dirumuskan pada bab sebelumnya antara lain:

1. Pengabdi memberikan pelatihan berbentuk ceramah dan praktek langsung kepada pekerja PT Mandom Indonesia Batam mengenai bentuk prinsip kerjasama dalam bahasa Inggris sehingga pekerja dapat memahami dan mempraktekkan dalam komunikasi sehari-hari saat menyambut tamu asing yang datang ke perusahaan;

2. Pengabdi memberikan pelatihan berbentuk ceramah, diskusi dan praktek langsung kepada pekerja PT Mandom Indonesia Batam mengenai bentuk bahasa sapaan dalam bahasa Inggris sehingga pekerja dapat memahami dan mempraktekkan bagaimana menyapa tamu asing sesuai dengan kaedah bahasa Inggris yang benar dalam komunikasi sehari-hari saat menyambut tamu asing yang datang ke perusahaan;

Sebagai pendukung dalam menerapkan metode tersebut diatas, Pengabdi memberikan form development test sebagai salah satu bahan yang bisa dijadikan sebagai tolak ukur dalam menilai peningkatan kemampuan pekerja dalam penguasaan materi yang diberikan

Untuk melihat sejauh mana pencapaian kegiatan dalam pengabdian ini dan sebagai perbaikan dan penyempurnaan untuk kegiatan pengabdian dimasa yang akan datang, peneliti akan melakukan evaluasi pelaksanaan kegiatan pengabdian yang meliputi antara lain: 
Jurdimas (Jurnal Pengabdian Kepada Masyarakat) Royal

Vol. IV No. 2, Des 2018, hlm. 27 - 32

ISSN 2407-1811 (Print)

DOI: https://doi.org/10.33330/jurdimas.v2i1.101

ISSN 2550-0201 (Online)

Available online at http://jurnal.stmikroyal.ac.id/index.php/jurdimas

1. Tahap sebelum kegiatan

Pengabdi melihat adanya dukungan yang cukup besar dari pihak manajemen dalam mendukung kegiatan pelatihan ini. Hal ini dapat terlihat dari penyediaan fasilitas seperti ruangan, proyektor dan pengeras suara yang disediakan oleh pihak menajemen.

2. Tahap saat pelaksanaan kegiatan

Pada tahap kegiatan pengabdi melihat adanya dukungan dan motivasi yang cukup besar dari peserta dan manajemen dalam mengikuti pelatihan yang diadakan. Selama proses pelatihan mereka terlihat antusias dengan banyaknya pertanyaan yang diajukan dan terjadinya diskusi selama proses pelatihan. Pelatihan menjadi lebih menarik karna didukung oleh fasilitas yang disediakan seperti proyektor,pengeras suara dan ruangan yang cukup nyaman.

3. Tahap setelah kegiatan

Pada tahap ini, pengabdi melihat dampak perubahan yang terjadi pada peserta yang mengikuti pelatihan. Hal tersebut terlihat mereka sudah mulai membiasakan diri untuk mepraktekkan materi-materi yang disampaikan pada saat pelatihan.

\section{PEMBAHASAN}

Pengabdian yang dilakukan oleh pengabdi dalam kegiatan pelatihan yang dilakukan di PT Mandom Indonesia mendapat perhatian dan kesan yang baik oleh seluruh pekerja setempat. Antusias pekerja di PT Mandom Indonesia terhadap kegiatan tersebut dapat terlihat dari cukup banyaknya pekerja yang hadir pada saat pelaksanaan pengabdian. Pada saat pelaksanaan pelatihan beberapa pekerja bertanya tentang peranan bahasa Inggris kedepan dan praktek penerapan bahasa Inggris sebagai frontliner di perusahaan mereka yang di pandu langsung oleh pengabdi. Dari hasil yang diperoleh dapat disimpulkan bahwa pekerja yang mengikuti pelatihan dapat menerapkan prinsip-prinsip komunikasi dalam bahasa Inggris dalam menyambut tamu diperusahaan mereka.

Dalam menjalankan aktifitasnya sehari-hari manusia akan selalu bertemu dan berinteraksi dengan orang lain. Dalam berinteraksi dengan orang lain, manusia menggunakan bahasa sebagai media komunikasi. Di dalam komunikasi yang wajar, masing-masing pihak yang terlibat, yaitu antara penutur dan mitra tutur akan selalu berusaha menyampaikan tuturannya secara efektif dan efisien. Seorang penutur akan berusaha agar tuturannya selalu relevan dengan konteks, jelas dan mudah dipahami, padat dan ringkas dan selalu pada persoalan sehingga tidak menghabiskan waktu lawan bicara (Karim, 2018)

Agar tuturan -tuturan dapat diutarakan dapat diterima oleh lawan bicaranya, penutur pada lazimya mempertimbangkan secara seksama berbagai faktor pragmatik yan terlibat atau mungkin terlibat dalam suatu proses komunikasi tersebut. Secara sederhana ada tiga aspek yang dipertimbangkan oleh penutur dan lawan tutur. Aspek-aspek itu adalah prinsip kerjasama, prinsip kesopanan dan parameter pragmatik. Berikut akan diulas salah satunya, yaitu prinsip kerjasama.

(Crabtree, 2013) bahwa wacana yang wajar dapat terjadi apabila antara 
Jurdimas (Jurnal Pengabdian Kepada Masyarakat) Royal

Vol. IV No. 2, Des 2018, hlm. 27 - 32

ISSN 2407-1811 (Print)

DOI: https://doi.org/10.33330/jurdimas.v2i1.101

ISSN 2550-0201 (Online)

Available online at http://jurnal.stmikroyal.ac.id/index.php/jurdimas

penutur dan petutur patuh pada prinsip kerja sama komunikasi. Prinsip kerja sama tersebut terdiri dari empat maksim percakapan (conversational maxim), yaitu: maksim kuantitas (maxim of quantity), maksim kualitas (maxim of quality), maksim relevansi (maxim of relevance) dan maksim pelaksanaan (maxim of manner).

Contoh penerapan prinsip komunikasi dapat dijumpai dalam kalimat bahasa Inggris sebagai berikut : (3) John put on his raicoat, picked up his umbrella from the table near the door, turned off the lights, put out the cat, got ready for his ten-minute walk to the bus-stop (4) John went out. Dalam tuturan yang wajar kalimat (3) dianggap terlalu panjang. Oleh karena itu untuk mengungkapkan konsep yang sama, tuturan (4) cenderung lebih digunakan.

Dengan maksim ini, para peserta pertuturan diharapkan untuk berbicara secara langsung, tidak kabur, tidak taksa dan tidak berlebih-lebihan serta runtut. Dalam wacana tuturan seharihari sering dapat dijumpai seorang penutur yang dengan sengaja tidak mengindahkan maksim ini, seperti yang terlihat pada dialog yang diambil dari (Parker, 1986) di bawah ini:

A: Let's stop and get something

to eat.

B: Okey, but not M-C-D-O-N-A-L-DS

Dalam dialog (10), ejaan dalam tuturan

B tersebut bertujuan untuk membuat anak yang menggemari Mc. Donalds tidak menyadari bahwa orangtuanya tidak ingin makan di Mc. Donalds.Seorang penutur harus menafsirkan kata-kata yang digunakan oleh lawan bicaranya. Secara taksa (ambigu) berdasarkan konteks pemakaiannya. Hal ini berdasarkan prinsip ketaksaan (ambiguitas) tidak akan muncul bila kerjasama antara peserta tindak tutur selalu dilandasi oleh pengamatan yang seksama terhadap kriteria-kriteria pragmatik yang digariskan oleh Leech dengan konsep situasi tuturnya. Dialog di bawah ini memberikan gambaran yang nyata mengenai kalimat taksa

A: Mas aslinya mana?

B: Saya aslinya Purworejo, Mbak.

A: Aduh, mas ini GR banget. Maksud saya, KTP asli saya mana?

Dialog tersebut sering terjadi ketika (A) sedang memfotokopi KTP di sebuah tempat fotokopi di Jogja. Setelah KTP selesai difotokopi, (A) bermaksud meminta KTP yang asli dengan mengatakan "Mas, aslinya mana?" dan ternyata ditafsirkan keliru oleh (B) karena dia menyangka bahwa (A) menanyakan asal-usul dia. Tuturan yang bersifat taksa seperti ini sering terjadi dalam kehidupan seharihari dan dapat membuat malu bagi pihak yang salah menafsirkan sebuah tuturan. Oleh karena itu, seyogyanya para peserta tutur menyadari bahwa hanya dengan memberikan kontribusi yang kooperatif maka sebuah komunikasi dapat berjalan dengan wajar.

Dalam berkomunikasi seharihari, pelaksanaan maksim-maksim tersebut dapat dibedakan ke dalam dua cara, yakni dengan menaati (observing) ataupun dengan tidak menaati maksim. Kegiatan tidak menaati maksim dapat dibedakan menjadi dua, antara lain, melakukan pelanggaran terhadap maksim (violating) atau membuat mengambang (flouting). 
Jurdimas (Jurnal Pengabdian Kepada Masyarakat) Royal

Vol. II No. 1, Jan 2019, hlm. 27 - 32

ISSN 2614-7912 (Print)

DOI: https://doi.org/10.33330/jurdimas.v2i1.101

ISSN 2622-3813 (Online)

Available online at https://jurnal.stmikroyal.ac.id/index.php/jurdimas

\section{KESIMPULAN}

Komunikasi merupakan akibat yang lebih jauh dari ekspresi diri. Komunikasi tidak akan sempurna bila ekspresi diri kita tidak diterima atau dipahami oleh orang lain. Dengan komunikasi pula kita mempelajari dan mewarisi semua yang pernah dicapai oleh nenek moyang kita, serta apa yang dicapai oleh orang-orang yang sezaman dengan kita. Sebagai alat komunikasi, bahasa merupakan saluran perumusan maksud kita, melahirkan perasaan kita dan memungkinkan kita menciptakan kerja sama dengan sesama warga. Ia mengatur berbagai macam aktivitas kemasyarakatan, merencanakan dan mengarahkan masa depan kita

Pada saat kita menggunakan bahasa sebagai alat komunikasi, kita sudah memiliki tujuan tertentu. Kita ingin dipahami oleh orang lain. Kita ingin menyampaikan gagasan yang dapat diterima oleh orang lain. Kita ingin membuat orang lain yakin terhadap pandangan kita. Kita ingin mempengaruhi orang lain. Lebih jauh lagi, kita ingin orang lain membeli hasil pemikiran kita. Jadi, dalam hal ini pembaca atau pendengar atau khalayak sasaran menjadi perhatian utama kita. Kita menggunakan bahasa dengan memperhatikan kepentingan dan kebutuhan khalayak sasaran kita. Pada saat kita menggunakan bahasa untuk berkomunikasi, antara lain kita juga mempertimbangkan apakah bahasa yang kita gunakan laku untuk dijual. Oleh karena itu, seringkali kita mendengar istilah "bahasa yang komunikatif".

Untuk dapat menghasilkan komunikasi yang baik antara penutur dan tertutur maka diperlukan pemahaman antar kedua belah pihak mengenai peranan prinsip kerjasama (cooperative principle) dan kata sapaan (address forms) di dalam komunikasi sehari hari. Penerapan kedua prinsip tersebut di atas diyakini dapat menghindari kesalahpahaman yang sering terjadi dalam berkomunikasi.

\section{UCAPAN TERIMA KASIH}

Kegiatan pengabdian kepada masyarakat ini tentunya, tak terlepas dari bantuan berbagai pihak, untuk itu ucapan terima kasih kami sampaikan kepada:

1. LPPM Universitas Putera batam sebagai penyelenggara kegiatan.

2. Bapak Pimpinan PT Mandom Batam Indonesia atas dukungannya dalam pelaksanaan pengabdian.

Tim pengabdian kepada masyarakat yang telah bekerjasama dengan baik, sehingga kegiatan dapat berjalan lancar dan sukses

\section{DAFTAR PUSTAKA}

Crabtree. (2013). Meaning and Context Language Files. Colombia: Ohio State University Press.

Karim, S. A. (2018). Analysis On Cooperative Principle And Politeness Principle In Guest Complaining At X Hotel In KutaBali A, (February 2017).

Parker, F. (1986). Linguistics for Non Linguist. London: Taylor \& Francis. 